\title{
Optimization of Blending Parameters and Fiber Size of Kenaf-Bast-Fiber-Reinforced the Thermoplastic Polyurethane Composites by Taguchi Method
}

\author{
Y. A. El-Shekeil, ${ }^{1}$ S. M. Sapuan, ${ }^{1,2}$ M. D. Azaman, ${ }^{1,3}$ and M. Jawaid ${ }^{2}$ \\ ${ }^{1}$ Department of Mechanical and Manufacturing Engineering, Universiti Putra Malaysia (UPM), 43400 Serdang, Selangor, Malaysia \\ ${ }^{2}$ Laboratory of Biocomposite Technology, Institute of Tropical Forestry and Forest Products (INTROP), \\ Universiti Putra MalAysia (UPM), 43400 Serdang, Selangor, Malaysia \\ ${ }^{3}$ School of Manufacturing Engineering, Universiti Malaysia Perlis, 02600 Arau, Perlis, Malaysia
}

Correspondence should be addressed to S. M. Sapuan; drsapuan@yahoo.com

Received 21 October 2013; Accepted 25 November 2013

Academic Editor: Riza Wirawan

Copyright (C) 2013 Y. A. El-Shekeil et al. This is an open access article distributed under the Creative Commons Attribution License, which permits unrestricted use, distribution, and reproduction in any medium, provided the original work is properly cited.

\begin{abstract}
"Kenaf-fibers- (KF-)" reinforced "thermoplastic polyurethane (TPU)" composites were prepared by the melt-blending method followed by compression molding. Composite specimens were cut from the sheets that were prepared by compression molding. The criteria of optimization were testing the specimens by tensile test and comparing the ultimate tensile strength. The aim of this study is to optimize processing parameters (e.g., processing temperature, time, and speed) and fiber size using the Taguchi approach. These four parameters were investigated in three levels each. The L9 orthogonal array was used based on the number of parameters and levels that has been selected. Furthermore, analysis of variance (ANOVA) was used to determine the significance of different parameters. The results showed that the optimum values were $180^{\circ} \mathrm{C}, 50 \mathrm{rpm}, 13 \mathrm{~min}$, and $125-300$ micron for processing temperature, processing speed, processing time, and fiber size, respectively. Using ANOVA, processing temperature showed the highest significance value followed by fiber size. Processing time and speed did not show any significance on the optimization of $\mathrm{TPU} / \mathrm{KF}$
\end{abstract}

\section{Introduction}

Natural-fiber-reinforced polymer composites are gaining great interest by researchers and industry due to advantages such as renewability, reduction in weight and cost, and less abrasiveness to equipment [1]. Compatibility between natural fibers and matrices always comes in the interface when talking about natural fiber composites. The hydrophobic nature of most polymers used in this sector against hydrophilicity of natural fibers causes fiber-matrix incompatibility (i.e., lack of adhesion and wettability between fiber and matrix). Kenaf plant is an annual plant that can be harvested 2-3 times a year. It can grow to reach 3-4 meters within 4-5 months. Kenaf plant has three layers: bast, core, and pith. Kenaf bast represents one-third of the plant. Core and pith represent the rest. Kenaf bast fiber has been reported to have superior mechanical properties than those the other parts of the plant [2]. Polyurethane is hydrophilic, and thus the issue that always arises (incompatibility) will not be a problem when compounding it with natural fibers [3]. Previously several researchers reported about naturalfibers-reinforced polyurethane (PU) thermosets [3-9]. TPU has been compounded with synthetic fibers such as glass, aramid, and carbon fibers [10-12]. Natural-fibers-reinforced thermoplastic polyurethane (TPU) composites were studied by the authors [13-19]. It was found that kenaf fibers were compatible with TPU.

Development of new composites using an internal mixer requires proper settings for parameters such as temperature, time, and speed in order to get the best results. Temperature is critical in processing; if it is low, it will lead to nonhomogeneous distribution of fibers. In contrast, higher temperature might lead to thermal degradation of the fibers as well as the matrix. Optimizing mixing time is also essential, 
TABLE 1: Properties of thermoplastic polyurethane (TPU).

\begin{tabular}{lccc}
\hline Hardness & $\begin{array}{c}\text { Tensile } \\
\text { strength }\end{array}$ & $\begin{array}{c}\text { Specific } \\
\text { gravity }\end{array}$ & $\begin{array}{c}\text { Melting } \\
\text { temperature }\end{array}$ \\
\hline $55 \mathrm{D}$ & $48 \mathrm{MPa}$ & 1.21 & $210^{\circ} \mathrm{C}$ \\
\hline
\end{tabular}

TABLE 2: The parameters for three levels of selected factors.

\begin{tabular}{lccc}
\hline Factors & Level 1 & Level 2 & Level 3 \\
\hline Melting temperature, A $\left({ }^{\circ} \mathrm{C}\right)$ & 180 & 190 & 200 \\
Speed, B (rpm) & 30 & 40 & 50 \\
Time, C (min) & 11 & 13 & 15 \\
Size, D (micron) & $<125$ & $125-300$ & $300-425$ \\
\hline
\end{tabular}

TABLE 3: L9 orthogonal array.

\begin{tabular}{lllll}
\hline Trail no. & \multicolumn{3}{c}{ Column no. } \\
\hline 1 & A & B & C & D \\
2 & 1 & 1 & 1 & 1 \\
3 & 1 & 2 & 2 & 2 \\
4 & 1 & 3 & 3 & 3 \\
5 & 2 & 1 & 2 & 3 \\
6 & 2 & 2 & 3 & 1 \\
7 & 2 & 3 & 1 & 2 \\
8 & 3 & 1 & 3 & 2 \\
9 & 3 & 2 & 1 & 3 \\
\hline
\end{tabular}

since in short mixing time homogeneous distribution might not take place. On the other hand, longer processing time causes thermal degradation of the matrix and breakage of polymer chains, due to shear stress and temperature. Moreover, processing speed might lead to breakage of the fibers if high speed is applied. Low speed is inadequate to mix the compounds well. Fiber size (i.e., aspect ratio) used in composite materials significantly affects the mechanical properties of the composite [20].

In the previous studies by the authors choosing the best parameters and fiber size was optimized in sequence, each one at a time (i.e., optimizing temperature, speed then time and finally fiber size), but there was no method that can give a combination of optimized parameters [13]. The authors found that kenaf-fibers-reinforced TPU is promising and decided to use a proper method to optimize processing parameters and fiber size. The aim of this study is to optimize processing parameters and fiber size of TPU/KF composites by using the Taguchi method to have a combination of optimized parameters. Furthermore the significance of parameters will be determined using ANOVA.

\section{Materials}

Polyester based thermoplastic polyurethane (TPU) was supplied by Bayer Co. (Malaysia) Sdn Bhd, Petaling Jaya, Selangor, Malaysia. The properties of TPU are summarized in Table 1. Kenaf bast fiber was obtained from KEFI (M) Sdn Bhd, Setiu, Terengganu, Malaysia.
TABLE 4: The combination parameters for the effective factors.

\begin{tabular}{lcccc}
\hline Trail no. & $\begin{array}{c}\text { Temperature } \\
\mathrm{A}\left({ }^{\circ} \mathrm{C}\right)\end{array}$ & $\begin{array}{c}\text { Speed } \\
\mathrm{B}(\mathrm{rpm})\end{array}$ & $\begin{array}{c}\text { Time } \\
\mathrm{C}(\mathrm{min})\end{array}$ & $\begin{array}{c}\text { Size } \\
\mathrm{D}(\text { micron})\end{array}$ \\
\hline 1 & 180 & 30 & 11 & $<125$ \\
2 & 180 & 40 & 13 & $125-300$ \\
3 & 180 & 50 & 15 & $300-425$ \\
4 & 190 & 30 & 13 & $300-425$ \\
5 & 190 & 40 & 15 & $<125$ \\
6 & 190 & 50 & 11 & $125-300$ \\
7 & 200 & 30 & 15 & $125-300$ \\
8 & 200 & 40 & 11 & $300-425$ \\
9 & 200 & 50 & 13 & $<125$ \\
\hline
\end{tabular}

\section{Methods}

3.1. Preparation of Fiber. Bast fiber was extracted from core by a mechanical decortication method. Fibers were pulverized and then segregated into three different sizes (300-425, $125-300$, and $<125 \mu \mathrm{m}$ ) using an automatic shaker sieve; using mesh 40-50, 50-120, and 120 .

3.2. Preparation of Composite. TPU/KF composite was mixed using a Haake Polydrive R600 internal mixer. The matrix was mixed in the mixer until stabilization of torque, and then fiber was added into the mixer. The fiber loading was fixed at $30 \%$ wt. After mixing the materials using the internal mixer, the compression molding process was used to form the sample sheets. The material was hot-pressed at $190^{\circ} \mathrm{C}$ for $10 \mathrm{~min}$ after preheating for $7 \mathrm{~min}$ at the same temperature. After that the sample was cool-pressed at $25^{\circ} \mathrm{C}$ for $5 \mathrm{~min}$.

3.3. Tensile Testing. Tensile properties were measured using an Instron 3365 machine, according to ASTM D 638. The specimens were prepared by cutting them into dumbbell shapes using a hydraulic cutter machine. Five specimens were tested with a crosshead speed of $5 \mathrm{~mm} / \mathrm{min}$.

3.4. The Taguchi Approach. The Taguchi method is well known by simplification of experimental plan and feasibility of study of interaction between various parameters. In this method a less number of experiments are carried out; hence, time and cost are reduced considerably. Main effect analysis is performed based on the average output of the quality characteristic at each parameter level. Analysis of variance (ANOVA) is used after that to appoint the significance and contribution of each of the processing parameters towards the output characteristic. Using the main effect and ANOVA a prediction of the best combination of optimum parameters can be calculated.

3.5. Selecting of Processing Parameters and Fiber Size. Three different temperatures $\left(180,190\right.$, and $\left.200^{\circ} \mathrm{C}\right)$ were examined. 
TABLE 5: Summary of the experimental results.

\begin{tabular}{|c|c|c|c|c|c|c|}
\hline Trail no. & Temperature A $\left({ }^{\circ} \mathrm{C}\right)$ & Speed B (rpm) & Time C (min) & Size D (micron) & Tensile strength (MPa) & $S / N$ \\
\hline 1 & 180 & 30 & 11 & $<125$ & 18.185 & 25.152 \\
\hline 2 & 180 & 40 & 13 & $125-300$ & 23.720 & 27.481 \\
\hline 3 & 180 & 50 & 15 & $300-425$ & 24.058 & 27.580 \\
\hline 4 & 190 & 30 & 13 & $300-425$ & 17.982 & 25.074 \\
\hline 5 & 190 & 40 & 15 & $<125$ & 12.265 & 21.751 \\
\hline 6 & 190 & 50 & 11 & $125-300$ & 20.153 & 25.985 \\
\hline 7 & 200 & 30 & 15 & $125-300$ & 12.036 & 21.403 \\
\hline 8 & 200 & 40 & 11 & $300-425$ & 11.972 & 21.439 \\
\hline 9 & 200 & 50 & 13 & $<125$ & 12.888 & 21.896 \\
\hline
\end{tabular}

There are some reasons behind choosing these temperatures. Temperatures less than $180^{\circ} \mathrm{C}$ are much less than the melting temperature of the matrix, which will result in nonhomogeneous mixing. Moreover, temperatures more than $200^{\circ} \mathrm{C}$ will be critical for natural fibers; thermal degradation might start affecting mechanical properties of the natural fibers [21]. Three different times $(11,13$, and $15 \mathrm{~min})$ were examined. Choosing these processing times was based on observation of the torque in the mixer. The torque gives a precise image of the condition of compounds inside the mixer. If the torque is not stabilized, this indicates that ingredients have not been sufficiently mixed, which will lead to poor dispersion. In contrast if the compounds are kept mixing for long time after stabilization of the torque, this may lead to thermal degradation and breakage of matrix chains. Fibers also break due to shear stress and temperature. Thus, the overall performance of the composite will be affected [20]. Finally, three speeds of mixing (30, 40, and $50 \mathrm{rpm})$ were chosen. It is thought that low speeds will not produce a homogenous mixture while high speeds may cause breakage of fibers. Finally, fiber size was also one of the parameters chosen due to its influence on the strength of the composite. Three fiber sizes $(300-425,125-300$, and $<125 \mu \mathrm{m})$ were chosen. Effect of blending parameters and fiber size was studied based on tensile strength as an essential test that indicates fiber-matrix interfacial bonding. Three levels are selected for each parameter as shown in Table 2. The L9 orthogonal array, based on the Taguchi method (Table 3) will be used based on the number of factors and levels that has been selected previously. Nine experiments have been done with combination of different parameters as shown in Table 4.

\section{Results and Discussion}

After mixing kenaf with TPU in the internal mixer, hot press machine was used to produce sheets of one millimeter thickness. Dog-bone-shaped tensile specimens were cut from the sheets using pneumatic cutter. Since tensile strength is the criterion that was chosen to study the optimum parameters, then in determination of $S / N$ ratio, the larger the better quality characteristic has been selected.
TABLE 6: Average of $S / N$ ratio.

\begin{tabular}{lccc}
\hline Factor & Level 1 & Level 2 & Level 3 \\
\hline Temperature A $\left({ }^{\circ} \mathrm{C}\right)$ & 26.738 & 24.270 & 21.579 \\
Speed B (rpm) & 23.877 & 23.557 & 25.153 \\
Time C (min) & 24.192 & 24.817 & 23.578 \\
Size D (micron) & 22.933 & 24.956 & 24.698 \\
\hline
\end{tabular}

For the bigger the better quality characteristic,

$$
\begin{array}{r}
S / N=-10 \log (\mathrm{MSD}), \\
\text { where } \operatorname{MSD}(Q C=B)=\frac{\sum_{i=1}^{n}\left(1 / y_{i}\right)^{2}}{n},
\end{array}
$$

where "MSD" is the mean square deviation, " $y$ " the observation or data, and " $n$ " is the number of tests in a trail.

The results that were calculated for tensile strength and $S / N$ are summarized in Table 5 . From the data in Table 5 the average $S / N$ ratio can be determined. The average effect factors are shown in Table 6. An example of the average factors calculations is shown as follows.

For temperature we have

$$
\begin{aligned}
& \text { level } 1=((25.15+27.48+27.58) / 3)=26.738, \\
& \text { level } 2=((25.07+21.75+25.98) / 3)=24.270, \\
& \text { level } 3=((21.4+21.43+21.98) / 3)=21.579
\end{aligned}
$$

Based on the data in Table 6 , the $S / N$ response diagram can be plotted as shown in Figure 1. The best combination of parameters can be observed in Figure 1. The highest value from each figure represents the best level. Thus, level 1 from processing temperature $\left(180^{\circ} \mathrm{C}\right)$, level 3 from processing speed $(50 \mathrm{rpm})$, level 2 from processing time $(13 \mathrm{~min})$, and level 2 from fiber size 125-300 micron are the best.

The data in Table 5 are analyzed using ANOVA. In order to determine the relative contribution of each parameter relative variances are compared. ANOVA will compute the following quantities which are summarized in Table 7:

(i) degree of freedom (DOF),

(ii) dums of square, 
TABLE 7: ANOVA table.

\begin{tabular}{lccccc}
\hline Factor & DOF $(\mathrm{f})$ & Sum of square & Variance & F-ratio & \% contribution \\
\hline Temperature A $\left({ }^{\circ} \mathrm{C}\right)$ & 2 & 39.9374 & 19.9687 & - & 74.24093 \\
Speed B $(\mathrm{rpm})$ & 2 & 4.280777 & 2.140388 & - & 7.957674 \\
Time C (min) & 2 & 2.302038 & 1.151019 & - & 4.279333 \\
Size D (micron) & 2 & 7.274102 & 3.637051 & - & 13.52206 \\
f error & 0 & - & - & - & - \\
Serror & - & $-1.8 E-12$ & - & - \\
\hline
\end{tabular}

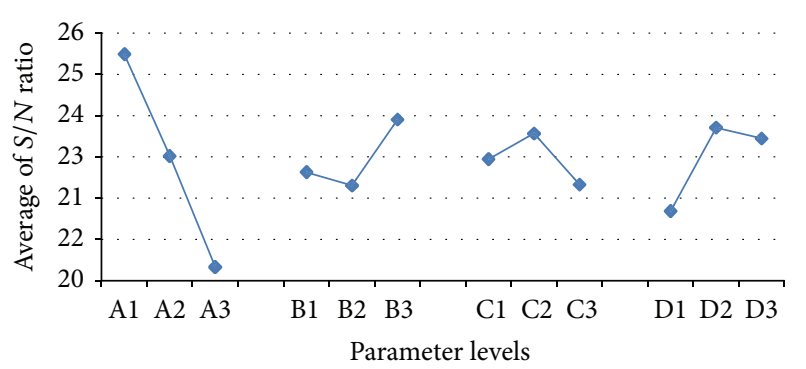

FIGURE 1: $S / N$ response for processing parameters temperature (A), processing speed (B), processing time (C), and fiber size (D).

(iii) variance,

(iv) F-ratio,

(v) percentage contribution.

From Table 7, it can be seen that the highest contribution from all the factors is the one from processing temperature which is $74.24 \%$; the contribution of fiber size comes next which is $13.52 \%$. Lastly the processing speed and time got low percentage, and thus these two factors can be considered insignificant.

By looking at the most significant factors affecting the production of TPU/KF it can be noted that temperature took the first place. This indicates the fact that the best interfacial bonding takes place when a proper temperature is selected, whereas high temperatures will negatively affect the matrix as well as the fibers. Kenaf fibers are better processed under $200^{\circ} \mathrm{C}$ to prevent thermal degradation. The matrix also when mixed under high temperatures will thermally degrade, as TPU used in this study is mainly produced for the extruding process which will take shorter time under the processing temperature. Thus, if the temperature is high, the matrix will be affected. After temperature, fiber size takes place in the significance of parameters affecting the process of producing TPU/KF. This is attributed to the importance of fiber size and aspect ratio (length/diameter) of short natural fibers in the field of natural fiber composites. Aspect ratio of the fibers used in this study is presented in a previous research by El-Shekeil et al. [14]. A small fiber size with low aspect ratio possessed larger surface area and left more surfaces nonreactive to the matrix; therefore, more stress points are created, resulting in reduced tensile strength [7]. Long fibers with high aspect ratio will cause poorer dispersion and agglomeration.

\section{Conclusions}

By using the Taguchi method nine trails were run. The optimum parameters that can result in the highest tensile strength are processing temperature $\left(180^{\circ} \mathrm{C}\right)$, processing speed $(50 \mathrm{rpm})$, processing time (13 $\mathrm{min})$, and fiber size $125-$ 300 micron. Among these factors ANOVA analysis calculations showed that processing temperature was the most significant parameter affecting the production of TPU/KF composites. The fiber size was the second parameter. Processing speed and time were not significant in producing the composite.

\section{References}

[1] H. M. Akil, M. F. Omar, A. A. M. Mazuki, S. Safiee, Z. A. M. Ishak, and A. Abu Bakar, "Kenaf fiber reinforced composites: a review," Materials and Design, vol. 32, no. 8-9, pp. 4107-4121, 2011.

[2] I. S. Aji, S. M. Sapuan, E. S. Zainudin, and K. Abdan, "Kenaf fibres as reinforcement for polymeric composites: a review," International Journal of Mechanical and Materials Engineering, vol. 4, no. 3, pp. 239-248, 2009.

[3] Ö. M. Seydibeyoğlu and K. Oksman, "Novel nanocomposites based on polyurethane and micro fibrillated cellulose," Composites Science and Technology, vol. 68, no. 3-4, pp. 908-914, 2008.

[4] A. K. Bledzki, W. Zhang, and A. Chate, "Natural-fibrereinforced polyurethane microfoams," Composites Science and Technology, vol. 61, no. 16, pp. 2405-2411, 2001.

[5] H. D. Rozman, K. R. Ahmadhilmi, and A. Abubakar, "Polyurethane (PU)-oil palm empty fruit bunch (EFB) composites: the effect of EFBG reinforcement in mat form and isocyanate treatment on the mechanical properties," Polymer Testing, vol. 23, no. 5, pp. 559-565, 2004.

[6] H. D. Rozman and G. S. Tay, "The effects of $\mathrm{NCO} / \mathrm{OH}$ ratio on propylene oxide-modified oil palm empty fruit bunch-based polyurethane composites," Journal of Applied Polymer Science, vol. 110, no. 6, pp. 3647-3654, 2008.

[7] H. D. Rozman, G. S. Tay, A. Abubakar, and R. N. Kumar, "Tensile properties of oil palm empty fruit bunch-polyurethane composites," European Polymer Journal, vol. 37, no. 9, pp. 1759$1765,2001$.

[8] K. A. M. Amin and K. H. Badri, "Palm-based bio-composites hybridized with kaolinite," Journal of Applied Polymer Science, vol. 105, no. 5, pp. 2488-2496, 2007.

[9] H. D. Rozman, Y. S. Yeo, G. S. Tay, and A. Abubakar, "The mechanical and physical properties of polyurethane composites based on rice husk and polyethylene glycol," Polymer Testing, vol. 22, no. 6, pp. 617-623, 2003. 
[10] S. Wilberforce and S. Hashemi, "Effect of fibre concentration, strain rate and weldline on mechanical properties of injection-moulded short glass fibre reinforced thermoplastic polyurethane," Journal of Materials Science, vol. 44, no. 5, pp. 1333-1343, 2009.

[11] C. Vajrasthira, T. Amornsakchai, and S. Bualek-Limcharoen, "Fiber-matrix interactions in aramid-short-fiber-reinforced thermoplastic polyurethane composites," Journal of Applied Polymer Science, vol. 87, no. 7, pp. 1059-1067, 2002.

[12] R. A. Corrêa, R. C. R. Nunes, and W. Z. Franco Filho, "Short fiber reinforced thermoplastic polyurethane elastomer composites," Polymer Composites, vol. 19, no. 2, pp. 152-155, 1998.

[13] Y. A. El-Shekeil, S. M. Sapuan, K. Abdan, and E. S. Zainudin, "Development of a new kenaf bast fiber-reinforced thermoplastic polyurethane composite," BioResources, vol. 6, no. 4, pp. 4662-4672, 2011.

[14] Y. A. El-Shekeil, S. M. Sapuan, K. Abdan, and E. S. Zainudin, "Influence of fiber content on the mechanical and thermal properties of Kenaf fiber reinforced thermoplastic polyurethane composites," Materials and Design, vol. 40, pp. 299-303, 2012.

[15] Y. A. El-Shekeil, S. M. Sapuan, E. S. Zainudin, and K. Abdan, "Effect of fiber loading on the mechanical properties of kenaf fiber reinforced thermoplastic polyurethane composite," Key Engineering Materials, vol. 471-472, pp. 1058-1063, 2011.

[16] Y. A. El-Shekeil, S. M. Sapuan, A. Khalina, E. S. Zainudin, and O. M. Al-Shuja'a, "Effect of alkali treatment on mechanical and thermal properties of Kenaf fiber-reinforced thermoplastic polyurethane composite," Journal of Thermal Analysis and Calorimetry, vol. 109, pp. 1435-1443, 2012.

[17] Y. A. El-Shekeil, S. M. Sapuan, E. S. Zainudin, and K. Abdan, "Effect of fiber loading on the mechanical properties of kenaf fiber reinforced thermoplastic polyurethane composite," Key Engineering Materials, vol. 471-472, pp. 1058-1063, 2011.

[18] S. Sapuan, F. L. Pua, Y. El-Shekeil, and F. M. AL-Oqla, "Mechanical properties of soil buried kenaf fibre reinforced thermoplastic polyurethane composites," Materials \& Design, vol. 50, pp. 467470, 2013.

[19] Y. A. El-Shekeil, A. Khalina, E. S. Zainudin, and O. M. Al-Shujaa, "Influence of chemical treatment on the tensile properties of kenaf fiber reinforced thermoplastic polyurethane composite," EXPRESS Polymer Letters, vol. 6, no. 12, pp. 10321040, 2012.

[20] C. Y. Lai, S. M. Sapuan, M. Ahmad, N. Yahya, and K. Z. H. M. Dahlan, "Mechanical and electrical properties of coconut coir fiber-reinforced polypropylene composites," Polymer, vol. 44, no. 4, pp. 619-632, 2005.

[21] G. Bogoeva-Gaceva, M. Avella, M. Malinconico et al., "Natural fiber eco-composites," Polymer Composites, vol. 28, no. 1, pp. 98107, 2007. 

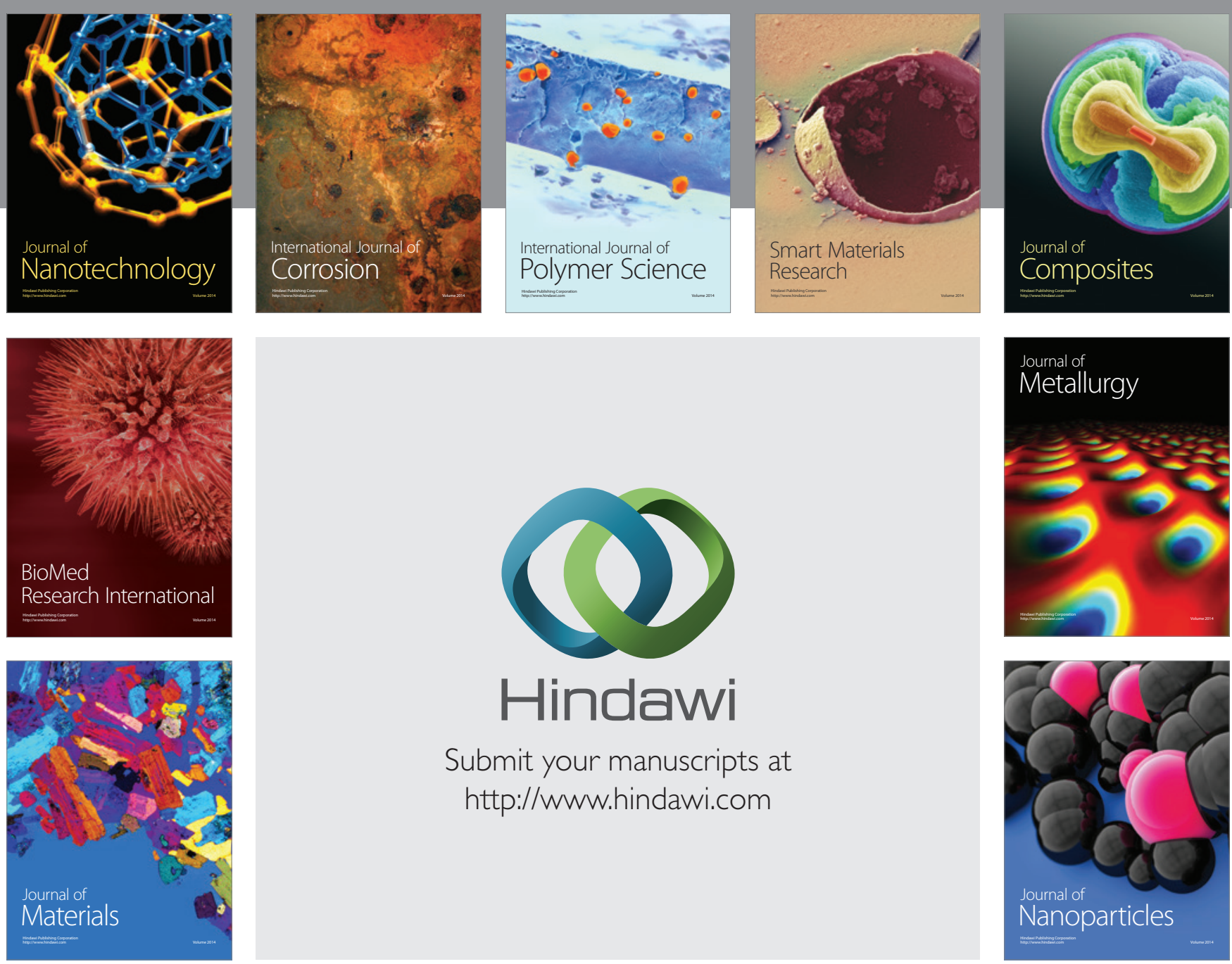

Submit your manuscripts at http://www.hindawi.com
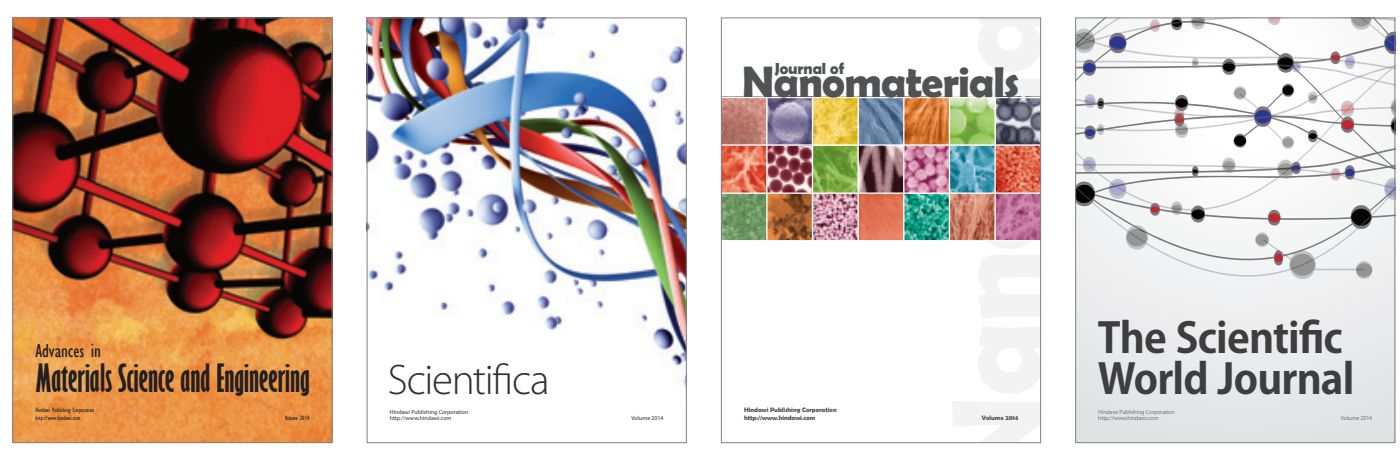

\section{The Scientific World Journal}
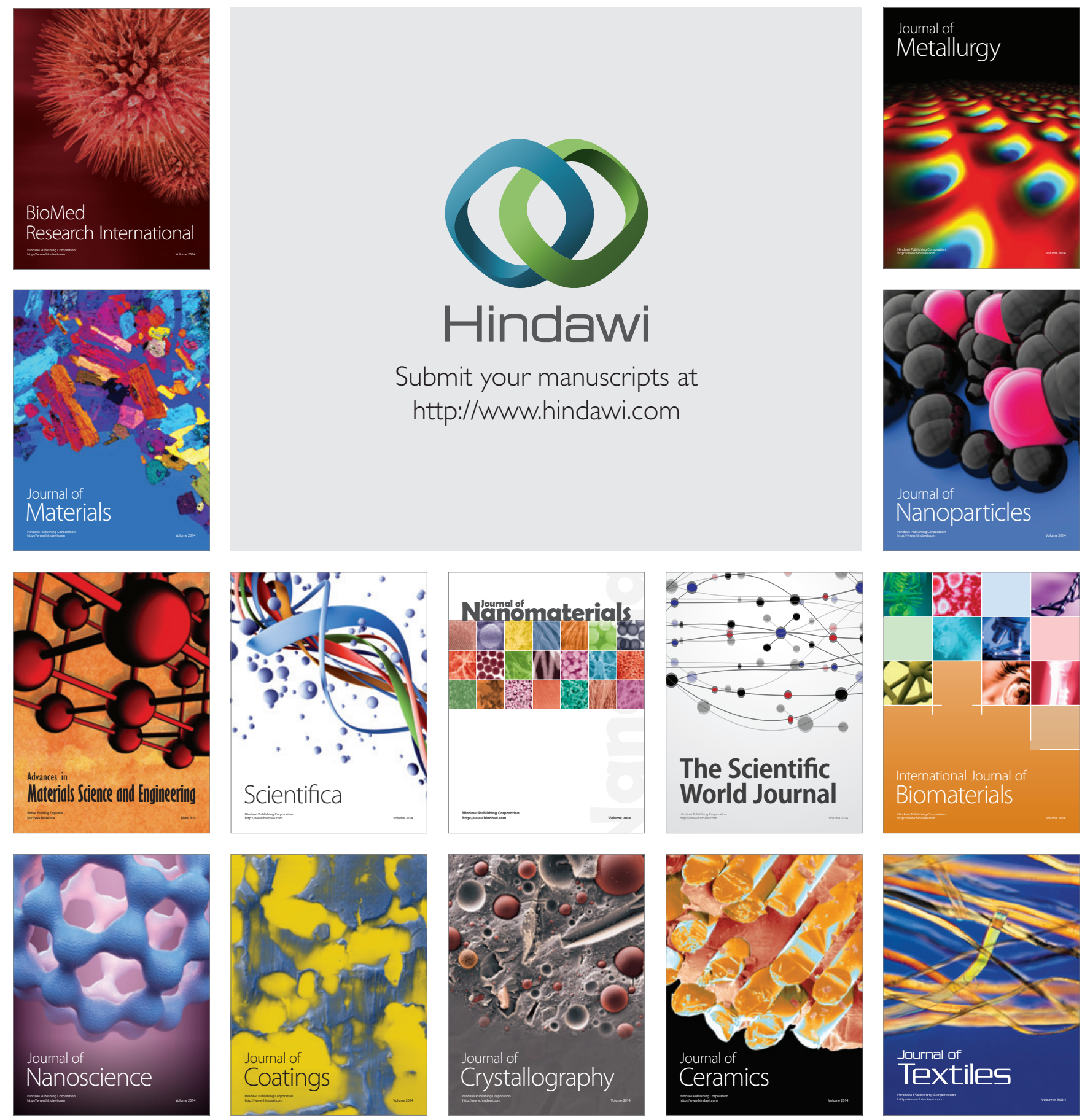